\title{
DEFECTIVE CHILDREN AND SPECIAL DAY SCHOOLS.
}

BY

A. DINGWALL FORDYCE, M.D., F.R.C.P.,

Physician to the Royal Liverpool Children's Hospital ; Certifying Officer to the Liverpool Education Authority.

Mens sana in corpore sano-such is the proof of complete success in medicine ; the two elements of normal life are inseparable, and in childhood determine the reciprocal and vital importance to each other of Education and Pædiatrics.

\section{History of Legislative Measures.}

In this country compulsory education was instituted by the passing of the Elementary Education Act in the year 1870.

As a result of experience gained in the working of this Act a Royal Commission was appointed in 1885 to deal with blind, deaf and dumb children, and such other cases as from special circumstances would seem to require exceptional methods of education. The Commissioners reported in 1889, and in Part 3 of their Report, stated that there was no clear line separating idiots and imbeciles : the difference was one of degree and not of kind. They came to the conclusion that there was a class of children of weak mind from birth or an early age, of whom a certain number required special educational arrangements to develop such faculties as they possessed, and they emphasized the importan e of manual and industrial training for such children. The Committee set out a scheme of education, the main credit for which was due to Dr. Shuttleworth, and this scheme practically holds the field to-day.

The Commissioners stated that the means requisite for improvement were :

(a) Physical. Good food, healthy surroundings, judicious medical and nursing care, and specially adapted physical exercises. Faulty personal habits have to be corrected.

(b) Moral. Kindness and firmness are essential to gain the confidence and obtain due control of the pupil. Religious feelings must be awakened and informed.

(c) Education.(1) School exercises based upon the axiom of Seguin that the 'education of the senses must precede the education of the mind.' (2) Industrial training: (a) Simple housework ; (b) Simple out-door work and garden and farm work; $(c)$ Sewing and certain handicrafts.

After making various suggestions with regard to the care and education of imbeciles, the Committee recommended that feeble-minded children should be separated from ordinary scholars in public elementary schools in order that they might receive special instruction; and further, that the attention of school authorities be particularly directed towards this object.

As a result of this Report the Elementary Education (Blind and Deaf Children) Act, 1893, was passed. 
In 1896 a Departmental Committee on Defective and Epileptic Children was appointed and in its report of 1898 dealt with the physically defective as well as the mentally defective and the epileptic. One of its main conclusions was :-

From the normal child down to the lowest idiot, there are all degrees of deficiency of mental power, and it is only a difference of degree which distinguishes the feeble-minded children, referred to in our inquiry, on the one side from the backward children who are found in every ordinary school, and, on the other side, from the children who are too deficient to receive proper benefit from any teaching which the school authorities can give.

The Committee called attention to the close association of the physically with the mentally defective, and in their Report stated that " a class of feebleminded children is also a collection of children physically defective."

The age of seven was recommended as the minimum age for admission to special classes, and as regards admission,-

... four persons ... should be present at the examination of children with a view to their admission to special classes, namely, the teacher of the school where the child has been, the medical officer of the School Authority, Her Majesty's Inspector, and the teacher of the special class; and a fifth, namely, the parent. should be given an opportunity of being present. The medical officer should receive from the teacher presenting the child a form duly filled up, containing a statement of the child's attainments, and he, after conference with the two teachers, and the Inspector, should make his recommendation to the School Authority.

As to the age up to which attendance at school should be required, the Committee reported as follows :-

We think that all children may be kept in the classes till fourteen, and that their retention till sixteen should depend upon the decision of the Managers made upon the recommendation of the medical officer, and should be conditional upon the arrangements being suitable for the older children.

This Report led to the Bill which was ultimately passed as the Elementary Education (Defective and Epileptic Children) Act, 1899. This Act was permissive in character and by it defective children were defined as children who not being imbecile and not merely dull and backward, are by reason of mental or physical defect incapable of receiving proper benefit from the instruction in the ordinary public elementary schools, but are not incapable, by reason of such defect, of receiving benefit from instruction in such special classes or schools as are in this Act mentioned.

A School Authority could deal with such children (1) by establishing special classes for them in some of its schools; (2) by boarding them out in houses near to special classes or schools ; (3) by establishing either day or boarding special schools for them. Parents are bound to send their defective and epileptic children between seven and sixteen to special schools and classes to the same extent as they are bound to send their normal children to ordinary schools. In 1904 a Royal Commission on the Care and Control of Feeble-Minded was appointed " to consider the existing methods of dealing with idiots and epileptics and with imbecile, feeble-minded or defective persons not certified under the Lunacy Laws," and the scope of this reference was later enlarged. The Committee reported in 1908 and the general conclusions of the Commissioners are set forth in Paragraph 9 of their Report which runs as follows :-

" Of the gravity of the present state of things there is no doubt. The mass.of facts that we have collected, the statements of our witnesses, and our own personal visits and investigations 
compel the conclusion that there are numbers of mentally defective persons whose training is neglected, over whom no sufficient .control is exercised, and whose wayward and irresponsible lives are productive of crime and misery, of much injury and mischief to themselves and to others, and of much continuous expenditure wasteful to the community and to individual families.

We find a local and 'permissive' system of public education which is available, here and there, for a limited section of mentally defective children, and which, even if it be useful during the years of training, is supplemented by no subsequent supervision and control, and is in consequence often misdirected and unserviceable. We find large numbers of persons who are committed to prisons for repeated offences, which being the manifestations of a permanent defect of mind, there is no hope of repressing, much less of stopping by short punitive sentences. We find lunatic asylums crowded with patients who do not require the careful hospital treatment that well-equipped asylums now afford, and who might be treated in many other ways more economically, and as efficiently. We find, also, at large in the population many mentally defective persons, adults, young persons and children, who are, some in one way, some in another, incapable of self-control, and who are therefore exposed to constant moral danger themselves, and become the source of lasting injury to the community.

In their discussion of what had been done since the passing of the Act of 1899 the Commissioners point out that up to September, 1906, it had been adopted by 87 Local Education Authorities. In the North of England there were 31 schools, of which 15 were in Lancashire, 5 of them in Liverpool. In Liverpool these five schools were opened in 1900, seven years before the institution of School Medical Inspection (1907), and medical work in connection with them was undertaken by specially appointed doctors.

The Commissioners made various important administrative recommendations which led to the introduction by the Government of a Mental Deficiency Bill in 1912, which was later withdrawn.

In 1913, however, an Act known as the Mental Deficiency Act (1913) was passed, to become operative from lst April, 1914.

The definitions of the classes of persons brought within the scope of the Act were set out in Section 1, which ran as follows :-

The following classes of persons who are mentally defective shall be deemed to be defective within the meaning of this Act:-

(a) Idiots; that is to say, persons so deeply defective in mind from birth or from an early age as to be unable to guard themselves against common physical dangers.

(b) Imbeciles; that is to say, persons in whose case there exists from birth or from an early age mental defectiveness not amounting to idiocy, yet so pronounced that they are incapable of managing themselves or their affairs, or, in the case of children, of being taught to do so.

(c) Feeble-minded persons; that is to say, persons in whose case there exists from birth or from an early age mental defectiveness, not amounting to imbecility, yet so pronounced that they require care, supervision and control for their own protection or for the protection of others, or, in the case of children, that they by reason of such defectiveness appear to be permanently incapable of receiving proper benefit from the instruction in ordinary schools.

(d) Moral Imbeciles; that is to say, persons who from an early age display some permanent mental defect coupled with strong vicious or criminal propensities on which punishment has had little or no deterrent effect.

The Act further provided as follows :-

The duties of a local education authority shall include a duty to make arrangements, subject to the approval of the Board of Education :-

(a) For ascertaining what children within their area are defective children within the meaning of this Act; 
(b) For ascertaining which of such children are incapable by reason of mental defect of receiving benefit from instruction in special schools or classes;

(c) For notifying to the local authority under this Act, the names and addresses of defective children with respect to whom it is the duty of the local education authority to give notice under the provisions hereinbefore contained.

Along with the Mental Deficiency Act the Government in 1913 attempted to pass an Elementary Education (Defective and Epileptic Children) Bill, to make the Act of 1899 compulsory, and otherwise to bring it into conformity with the Mental Deficiency Act. This Bill was not carried, but in the next Session the Elementary Education (Defective and Epileptic Children) Act, 1914, was passed.

By this Act the Act of 1899 was made compulsory, so far as concerned mentally defective children. (The compulsory powers as regards physically defective children did not become operative until the Education Act of 1918.) The duty then devolved upon local Education Committees of making arrangements and submitting them for approval to the Board of Education for carrying out work under the two Acts.

The Board of Education issued model arrangements for the guidance of Education Committees in framing arrangements. These model arrangements treated the medical officer as practically the one effective instrument for carrying out the arrangements. The Liverpool Education Committee, however, modified the model arrangements so as to give a more prominent position to their educational advisors, and they definitely appointed a supervisor of defective children to act with the medical certifying officer, and gave specific recognition to this officer in their arrangements.

The certifying officer's form of report on each child examined for mental deficiency is of a very elaborate character and includes details of family history; physical, scholastic, mental and moral personal history; detailed physical examination; emotional, scholastic and intelligence reactions; diagnosis and disposal recommended.

In 1917 the Board of Education revised their "Regulations for Special Schools" and in a prefatory memorandum stated, "The Board recognise that during the war it would be inopportune to introduce into the Regulations any new requirements..."

In 1924 the Board of Education issued a circular to local education Authorities in which, after emphasising the need for full ascertainment of all cases of mental defectives in the locality, the value of securing the notification of suitable cases of children about to leave the Special School at 16 is recalled.

In 1927 the Mental Deficiency Act, 1927, was passed, and by it the definition of mental defectives became as follows :-

(a) Idiots; that is to say, persons in whose case there exists mental defectiveness of such a degree that they are unable to guard themselves against common physical dangers.

(b) Imbeciles; that is to say, persons in whose case there exists mental defectiveness which, though not amounting to idiocy, is yet so pronounced that they are incapable of managing themselves or their affairs, or, in the case of children, of being tanght to do so. 
(c) Feeble-minded persons ; that is to say, persons in whose case there exists mental defectiveness which, though not amounting to imbecility, is yet so pronounced that they require care, supervision and control for their own protection or for the protection of others or, in the case of children, that they appear to be permanently incapable by reason of such defectiveness of receiving proper benefit from the instruction in ordinary schools.

(d) Moral defectives ; that is to say, persons in whose case there exists mental defectiveness coupled with strongly vicious or criminal propensities and who require care, supervision and control for the protection of others.

For the purposes of this section 'Mental defectiveness' means a condition of arrested or incomplete development of mind existing before the age of 18 years, whether arising from inherent causes or induced by disease or injury.

Certain very important alterations from the 1913 Act are herein contained.

In 1913 all grades of mental defect are " from birth or from an early age," and it was always difficult to decide the limits of ' early age' ; in 1927 the age is extended to 18 years and this greatly facilitates desirable action.

In 1913 under grade $(d)$ the term was Moral Imbecile, and the final clause after the word "propensities' read, " on which punishment has had little or no deterrent effect." In 1927 the term is changed to Moral Defective which is perhaps of particular value for some cases of post-encephalitis lethargica, and the criterion of reaction to punishment is done away with which facilitates preventive care.

In the case of feeble-minded children there remains the difficulty of decision as to what exactly is to be understood by " proper benefit from the instruction in ordinary schools."

Other important improvements embodied in the 1927 Act deal with supervision and after-care.*

Such in brief has been the legislative history of the development of Special Day Schools for Defective children.

\section{Present Position and Practice.}

What is the present position and practice?

In Liverpool, in addition to Special Day Schools for the Deaf and the Blind there are four Special Day Schools which are combined centres for a Physically Defective School and a Mentally Defective School, and one Special School which is a single one for the Mentally Defective.

The accommodation in these schools provides for 383 physically defective children and 608 mentally defective children, while the number of children on the school rolls is 477 physically defective and 766 mentally defective.

Liverpool is fortunate in having in its immediate vicinity various large Country Hospitals and Residential Schools, and so far as physically defective children are concerned full accommodation for day scholars is likely to exist so soon as the new Open Air Day School, now in preparation, is opened.

*For much of the foregoing I am indebted to a memorandum by Mr. Legge, late Director of Education, Liverpool. 
But so far as feeble-minded children are concerned, not only are the Special Day Schools at present crowded, but many children already certified cannot gain admission, and the new Special School which is to be opened shortly for older boys will only partly meet the call.

\section{The Certification of Physically Defective Children.}

In his paper on "The Day Special School from the point of view of the Administrator" read at the Conference of the National Special Schools Union, November, 1927, Mr. Newton said, "It is a common experience of administrators to find that hospital and private doctors give medical certificates of unfitness to attend school in respect of children who could be admitted with benefit to special schools. The practitioners often give the certificates with a knowledge of the elementary school system only in their minds. If they can be supplied with a description of the special schools of the neighbourhood, and it can be explained to them how these schools are equipped for dealing with defective or ailing children, the doctors will be glad to have the information and will often advise parents to let their children have the benefit of special school education."

As a rule children are sent to the certifying officer with a view to admission to a special school by a school medical officer, health visitor, head teacher, and occasionally parents.

The main types of cases admitted are those of quiescent surgical tuberculosis, paralysis (flaccid and spastic), congenital deformities and the after effects of rickets. In some parts of the country the schools contain many cases of severe cardiac trouble (congenital and acquired), also cases of debility and some of epilepsy, asthma, etc.

Cases of trivial deformity, or those with a complaint rendering their attendance at school likely to be very irregular, are, however, often more advantageously retained at an ordinary school with special allowances when necessary.

Of 483 children in the Liverpool special schools in 1927, only 16 suffered from, and were admitted because of, rheumatic disease of the heart, and more of the serious cardiac cases could with advantage be admitted.

Some cases of congenital deformity and of spastic paralysis are obviously and certainly mentally defective, and if fitted tor school education at all are naturally suitable for a school for mentally rather than physically defective children.

Other children of these types there are, whose mental capacity is hard to gauge, and in all such cases it is desirable that before admission to one or other type of school some index of mental power should be obtained.

Parents are sometimes very averse to having their children sent to a special school for physically defective children. They may see no reason why the child should not remain ' at his own school,' or they may positively object to sending him to 'a cripple school ' or ' a silly school' These two latter 
terms are specially liable to be vicariously used when schools are double centres. that is to say, when under one roof there is both a school for physically defective and a school for mentally defective children, however separate they may be.

It certainly seems that some teachers in ordinary schools are unduly nervous of having control of children wearing surgical appliances, and the story ot the child who was taken home by ambulance from the special school each afternoon, and yet each afternoon walked back to school and waved off the children going by a later ambulance is not without point.

Children certified as suitable for a school for physically defective children are taken to and from school by ambulance when necessary, and they get a good dinner in the middle of the day as well as extra nourishment at discretion

\section{The Certification of Mentally Defective Children.}

Children are recommended for examination by the certifying officer chiefly by school medical officers and head teachers, but also sometimes by Welfare workers or others, or at the request of the parents. Before such examination a full report is received from the head teacher regarding especially particulars of school attendance, scholastic attainments, and behaviour and disposition.

The child and his parent are then interviewed by a special officer who obtains full family, personal and domestic history, enquires into and observes personal and social functions and temperamental conditions, and finally obtains the child's intelligence quotient.

At some period thereafter the certifying officer examines the child in the presence of the Superintendent of Special Schools and of the parent, and having before him the reports of the head teacher, the school medical officer and the specially prepared form of information. His decision has to deal with the type or grade of mentality and the disposal of the child. He is here in the first placo faced with a problem which includes not only decision as to the inherent mental capacity of the child but also the extent to which it can be developed in the particular scholastic environment in which he finds himself. This last is a markedly varying factor both in its intrinsic quality and in its human relationship.

It must, necessarily therefore, sometimes happen that a certifying officer cannot conscientiously atter one examination make a final decision; and so with the borderline case, particularly in a young child, he sometimes gives a period of probation in the ordinary school, followed by a second examination and further report from the teacher.

(During 1927 I made a decision in 96 cases which I had placed on probation at ordinary Elementary Schools for periods of six months or longer. In 45 cases the decision was dull and backward, in 30 feeble-minded, in 4 physically defective, and in 17 probation was continued.)

While it is sometimes necessary to make use of probationary periods, it is advisable to do so as seldom as possible both for the sake of the individual and of the other scholars in the school in which he may be wrongly placed. As this is true of children who would be more fitly placed in special schools rather than in ordinary Elementary Schools, so is it equally true of children at the other 
end of the special school grade who would be more fitly certified as imbecile, and thus do work at occupation centres. The younger the child is suitably placed the better are his prospects, and the better can be the work of teachers all round. In all borderine cases and in cases where evidence is conflicting, the results of the Binet Simon tests are of great value.

Parents often object to their child being sent to a school for Mentally Defective Children. If backwardness on the part of the child is admitted at all, it is thought to be due to "spite of the teacher," "neglect of the teacher," delayed development, laziness, "like his father or mother," or, particularly in the case of Roman Catholics, "too much religion."

There is often also resentment at the prospect of retention in school till 16 instead of 14, and this is particularly marked when children are only submitted to the certitying officer in their later school years. Delay in admission to a special school because of lack of accommodation often tends to increase this sense of resentment.

There can be no doubt however that, once admitted, the children with very few exceptions enjoy the life of a special school, and most parents quickly learn to appreciate its value.

The Work of the Special Day School.

Generally speaking the educational advantages for scholars are :-

(a) The pupils get more individual attention from the teachers than do the pupils in the ordinary Elementary schools, because the average size of a class in a special school is $\mathbf{2 5}$.

(b) The teachers are specially trained.

(c) Schemes of 'literary' work are suited to the mental level of the pupils.

(d) More handwork is given than in the ordinary elementary schools, and this handwork leads to craftwork with a definite vocational tendency.

The curriculum set out in the "Special Regulations for Schools for Defective or Epileptic Children " by the Board of Education (1917) includes, inter alia:-

(d) . . . (it) should be adapted to the special conditions under which the children are being taught, and the teaching of such subjects as Arithmetic and English (including Geography and History) should be connected as far as possible with the manual occupations of the children.

The manual instruction, while of a strictly educational character, should be practical and related to the school life and surroundings. This applies in particular to the needlework, and also to the woodwork and metalwork, which should be closely related to the needs of the school and of the garden.

Wide scope is granted for individual school curricula, and in Liverpool it is customary after religious instruction in the morning to occupy the forenoon with instruction mainly in reading, writing and arithmetic, and to devote the afternoon to manual work. This holds true both in the physical and in the mental schools. 
All children in school are examined at least once a year by the certifying officer, and the year's scholastic progress is placed before him.

Sometimes it is found necessary to transfer a child from the physical to the mental school ; occasionally a child in the mental school makes such unexpected progress that it is found possible to decertify it and allow it to return to the public elementary schoool. When a child is found after full trial to be unable to benefit from the school he is certified as an imbecile, and if the parents are willing is recommended for instruction in an occupation centre.

During attendance at school the special supervision and the presence of a nurse in the school facilitate regular or continuous attendance at outpatient department or surgery.

Even so it cannot, I think, be justifiably said that the control of longcontinued treatment is satisfactory. We need much closer co-operation between whole-time official doctors and clinicians, and it is very desirable that the former should be granted time and opportunity to take a place on the staff of hospitals, and that the latter should be admitted and recompensed for official work. Treatment, except for quite trivial conditions, is not given at the schools.

After the age of fourteen some of the children become restless and anxious to leave school ; in other cases the parents want them to commence work. The jurisdiction of the Education Committee extends till the age of sixteen, but in some cases permission to leave earlier cannot in practice be gainsaid if a definite offer of work is in hand.

On leaving school at the age of sixteen the children are automatically referred to after-care Committees or in the case of appropriate feeble-minded children to the Mental Welfare Association in connection with the Board of Control.

Apart from deaf and blind children there are certain other classes of cases which necessarily demand special consideration and of these three appear to stand out conspicuously-

\section{1.-Epileptic Cases.}

These cases can generally speaking be placed in one of four categories, namely, where the epileptic fits are consequent upon (1) birth trauma, (2) simple primary amentia, (3) infantile cerebral paralysis, or (4) cases of idiopathic epilepsy.

Pyknolepsy in my experience is very uncommon. I have only seen three cases.

The deciding factor as to the fitness or otherwise of an epileptic child as scholar at a day school, be it ordinary elementary, P.D., or M.D., special school, is the liability to severe diurnal fits. If the history is only of a few fits at long intervals, if the fits are only nocturnal, or if the fits are invariably preceded by unmistakeable symptoms, any type of school fitted to the child's mental condition may be permissible.

If the fits are severe, frequent, or diurnal, no form of day school is advisable. 
But in a great many cases the type of school depends upon the presence or absence of long-continued and constant treatment. The 'leakage,' to use Sir George Newman's phrase, which occurs in the treatment of very many of them is deplorable. We agree that suitable education, and if possible ordinary education, is one of the most important needs of the epileptic child. But in many instances such education can only be obtained or continued it the child is under continuous medical treatment. Most of such children come sooner or later into the sphere of influence of the Special Schools Committee. They are defective children. As the Authority dealing with defective children, the Special Schools Committee is the natural link between, on the one hand, the preventive agencies of early childhood and the medical service of the ordinary elementary schools, and, on the other hand, with medical practitioners and hospitals. It occupies then from the medical standpoint an important central position. These epileptic children are among those who bring the Special Schools Committee into closest relationship with medical practitioners and hospitals. They cannot be satisfactorily educated unless such relationship is most intimate.

When children continue to have severe diurnal fits on full treatment, they are only suitable for a special Epileptic School, and such a school should be residential. Unfortunately it is common for institutions for educable epileptics to make feeble-mindedness a bar to entrance.

\section{2.-Post-encephalitic Cases.}

Under the terms of the Mental Deficiency Act (1927), she ag $>$ of the causation of mental defect, "whether arising from inherent causes or induced by disease or injury," is extended to eighteen years.

Apppropriate cases of cncephalitis lethargica can therefore be included under it. But the so-called " character cases" are cases equally unsuited for a Special Day School as for an ordinary Elementary School, and yet manyfor long, at least-are not certifiable as imbeciles. Some of these children have been given a period of probation in a special day school, with very unsatisfactory results. Some are now certifiable as moral defectives, but there is no means of special disposal of these children.

\section{3.-Rheumatic Cases.}

The treatment of active rheumatism and the prevention of permanent cardiac disease are accepted as matters of supervision and suitable hygiene for a prolonged period, a matter of years. To obtain this in very poor or unsatisfactory families, nothing short of a residential institution is of real avail.

If, on the other hand, the home is satisfactory, the mother intelligent and capable, and the child kept under regular and frequent supervision by a medical man, then in most cases the ordinary elementary school (with due precautions) is the most satisfactory school. If, however, the rheumatic child suffers trom serious permanent cardiac disease, a Special Day school is often the greatest boon and pleasure, 
The questions of corporal punishment for scholars in special day schools and the general control of the older children are matters of interest and difficulty. These children stay at school till they are sixteen, and some of them well before that time are in physique men and women.

I think we must all agree that for a healthy boy at the period of puberty, the daily school teacher should be a man and not a woman. For, particularly; the high-grade feeble-minded boy, a man teacher is still more necessary. It has not been my fortune to meet any body of women for whom my respect is higher than it is for the lady teachers in the special day schools, but I think their sex should in itself be a contra-indication for the duty of constantly teaching the older boys there. These youths should be under men, they should have some form of vocational training, and corporal punishment should not be entirely taboo. The high-grade feeble-minded boy is, as I have suggested, usually the most difficult type. Such a boy is sometimes not incapable of trading upon the fact that his naughtiness is treated with pity as being a sign of his feeble-mindedness.

A teacher in a special day school for feeble-minded children writes to me-

Moral suasion is lost upon a certain class of these feeble-minded children-in fact they ridicule it and scorn it. . . . The policeman or detective is no object of fear in any of their homes, in fact, to use their own language they have 'done' him so often and hoodwinked him, that his appearance is part of a game for them. They hold the law and those officers who enforce it in derision. . . . Knowing that a visit to the Court means in the majority of cases a warning only, they become more and more daring. . . . If they were made to feel punishment, then this readiness to offend would soon lessen.

On the other hand many children physically weakly, though with a weakness of an inconspicuous nature, are the children who must appear ' naughty' very often to a tired, hard-worked teacher. These are the children who may receive punishment of various sorts, but these are just the children for whom corporal punishment is essentially bad.

A teacher dealing with physically defective children who previously had been in ordinary elementary schools writes to me-

The results of caning seem so temporary that they don't seem worth while, even when they are not noticeably harmful. The children who are most often punished are $(a)$ those who are quite unable to tackle anything like the work they should be doing without great mental distress, because they have lost all confidence in themselves, or (b) children are punished for talking in class (including "giving cheek") and these children are usually found to be either in too high or too low a class. . . . I think that those who use the cane think that those who don't must be soft in their treatment of the children. This is not so; I am sure the very first thing to do is to require a very high standard of work and behaviour from, first yourself, and then the children. The two reasons for caning given by most teachers of big boys are (1) cruelty, and (2) sexual offences. Anything less logical than caning as a cure for either of these could hardly be found. It seems to me that a sound and consistently up-held philosophy of life, including really high ideals, is the only cure worth having, and the best of it is, that when it is faithfully applied, it succeeds every time.

With the development of Country Hospitals for long-continued cases the importance of coincident education was at once recognised, and to-day in all good class hospitals such instruction is provided. If a child misses through jllness one or more years of instruction at school, and at the end of this time 
is fit to return to an ordinary school, it is of immense importance that he should be able to take his place with children not too much his juniors. Otherwise he passes into the category of the dull or backward, and for these at present no adequate provision exists. But with the development of schools in hospitals it has become possible to transmit with the leaver from hospital such scholastic information as will prove most valuable in placing him in a suitable class in school, or in pointing to the type of school desirable. Such a plan of action should be much more employed than it is, and would prove particularly valuable in orthopædic cases. The sphere of the orthopædist is to-day a very wide one, and we are sometimes told that he deals only with mentally normal children, or with children whose mentality is merely impaired because of their orthopædic disability, and which is restored pari passu with effective orthopædic treatment.

But experience goes to show that even prolonged and successful orthopædic treatment cannot compensate for damaged cerebral tissue, and that in many cases, children suffering from orthopædic defects are feeble-minded children. It is of extreme importance that such feeble-mindedness should be recognised and the child properly placed in school.

Practitioners and the medical and surgical staff of hospitals cannot to-day avoid responsibility with regard to the type of education for which their patients are suited. Such education is an important part of treatment.

In all cases the hope must be to fit the child for the ordinary elementary school, but if not so fitted the sooner the child is properly placed in a special school the better its prospects are.

Suitable scholars at special schools for physically and for mentally defective children must of necessity be those children who can only be classed as medical and surgical failures-at least temporarily. The main aims of the schools must then be two : first, humanitarian, to fit the individual for a suitable safe niche in life, however humble; secondly, the protection of society, to keep unreliable or unsafe citizens under supervision or in segregation.

As regards the first I will quote two recent authorities-Davis (What Shall the Public Schools do for the Feeble-Minded? Harvard University Press: 1927), writes :-

If the mentally subnormal individual is to enter into successful competition with normal individuals in either unskilled or semi-skilled labour, he must receive that type of training which will prepare him for such competition. By receiving this rather diversified type of preliminary training he is enabled to compete on equal terms in a particular type of work with the normal individual who has not had the opportunity of such instruction. . . . If we admit that by means of special school training. the mentally retarded child has received the requisite training whereby the skill and strength necessary to enter into some gainful pursuit have leen acquired, even though he were so equipped, he could not hold any position for any length of time without having formed the habit of regularity. . . . After all, the primary object of prevocational training in the special school is the cultivation of an attitude of work-following dircctions, co-operation, dependableness, cheerfully sustained effort, and interest in the particular task. With these assets the defective child will be able to compete successfully with normal individuals and so become worth-while individuals in community life. 
Miss Anderson (Education of Defectives in the Public Schools, Harrap \& Co., Ltd., 1926), writes :-

The aim of training the defective is to help him succeed in the work he is able to do-in other words, to enable him to get a job at unskilled work, to do the work well, and to know enough to keep it even if the work is not altogether pleasing.

With regard to the second aim-supervision-this should commence from the day of leaving school. Before leaving, in some schools children are tested for Social Efficiency, while in Report No. 33 of the Industrial Fatigue Research Board, entitled " A Study in Vocational Guidance " based on work carried out under the auspices of the Medical Research Council, a " psychographic scheme" is given (drawn up by Dr. Cyril Burt) which consists of a detailed schedule for investigating individual cases.

Mr. Newton (National Special Schools Conference, 1927) has said :-

. . . the method of holding a "school leaving conference" towards the end of every school term will probably afford the best opportunity of gathering up all the information about "the golden lads and girls" who are at this stage of their lives inelegantly termed "leavers," and of placing these data at the disposal of the executive "work-seeker," be he the juvenile employment officer of the local education authority or an official of one of the Exchanges of the Ministry of Labour. In some places, the "leavers" with or without their parents, go to the juvenile employment office, or to the Exchange. This plan I believe to be much inferior, particularly for the discussion of the "first placing," to the plan of the official attending a school leaving conference held in the school building, when the "leavers" of the term, each with a parent especially invited (if possible personally invited by a Care Committee worker), can be seen in a succession of friendly interviews.

Without suitable after-care, without adequate supervision, much of the good of a special school is lost.

Most of these children require friendly help and guidance throughout life. The sphere of after-care work is so great that it is impossible as yet to deem it effectively carried out, and we have still to look forward to the time when this essential sequel to the work of the Special Day Schools will provide for the defective child his 'place in the sun.' 